through weighing have been attempted by Dr. Krafft with a chemical weight (Bunge), however without result, caused chiefly by the circumstance that he was unable to give the instrument the proper rest. The observations of the directions of the wind have been made by a weather-cock fixed on the top of a stripped fir tree, the force being registered by Beaufort's scale, and the velocity partly by Mohn's hand thermometer, which are used during the hourly observations, and partly by means of a Robinson anemometer placed on the roof of the dwelling-house, which is read once in twenty-four hours. Further, one of Hageman's anemometers is erected in the office, from which the conductor, made of indiarubber and lead pipes, is carried outside the house and along the flagstaff in such a manner that the absorbing point or tube is situated a couple of centimetres above the knob of the same. The observations with this anemometer have, however, not given so satisfactory results as might have been expected from my experiences in other places. The cause of this is no doubt the circumstance that the instrument used was not a new one, and consequently, perhaps, not very sensitive, while the position was, we found, not the most advantageous. On the bare ground we have placed two rain-gauges - the one square and the other roundwith a receiving surface of 225 square $\mathrm{cm}$. each. The rainfall here is very small, averaging only $267 \mathrm{~mm}$. per year, but during the past twelve months it has been rather less.

The measurement of the snowfall we have found almost an impossibility, on account of the frequent gales during the winter, which sweep the snow away as quicksand from one place and deposit large drifts in others.

Every month measurements of the temperature of the sea have been effected, in the Alten Fjord, with one of Negretti and Zambra's deep-sea thermometers. The depth is Ioo English fathoms, and the temperature read at every tenth fathom. We have during these researches discovered that from the bottom and Io to 20 fathoms upwards the temperature keeps constant throughout the year, whereas in the layers above this depth some very interesting variations occur with the seasons.

Last winter here has been milder than we anticipated, the lowest temperature registered being $-21^{\circ} \cdot 7 \mathrm{C}$., which was read by the minimum thermometer at 8 a.m. on December 31 , 1882 . Under high wind such a temperature is unpleasant enough, and with gales we have several times been favoured. Thus, on October 5 the velocity of the wind under a storm from the north-west was 26 metres per second, and on later occasions the anemometer has not seldom shown a velocity of from Io to 20 metres per second.

Our labours at this station are now approaching their completion, and it is satisfactory to me to be able to state that no accident has occurred to our instruments, the accuracy of which has been controlled throughout in various manners, and that the scientific researches have been continued during the entire year without a single interruption.

What the ultimate results of our researches during our sojourn here will be it is of course at the present moment an impossibility for me to state, but I feel confident that, when all the materials of research have been collected from the various circumpolar stations and compared, it will be found that the Norwegian station at Bossekop has formed an important link in the chain of international meteorological research around the Pole.

Bossekop, Finmarken, Norway, August

\section{A NATIONAL LABORATORY OF MARINE ZOOLOGY}

$\mathrm{I}_{\mathrm{T}}$ is pretty well understood that the Executive Committee of the London International Fisheries Exhibition of 1883 will have a sum of money in hand when all expenses connected with the Exhibition are paid, amounting to some thousands of pounds. The gentlemen who have organised and carried through this very successful enterprise are to be congratulated on the popularity which has attended the Exhibition and on the amount of interest which they have excited in all classes of the community in matters relating to our national fisheries. Not only this, but the Committee deserves hearty thanks for the valuable series of pamphlets on subjects connected with fisheries which it has printed and circulated far and wide. These pamphlets are for the most part reports of lectures delivered by highly competent specialists at the "Conferences" inaugurated by Prof. Huxley under the presidency of the Prince of Wales, and amongst them are such important essays as that of Prof. Hubrecht on oyster culture, of Dr. Day on the food of fishes, of Prof. Brown Goode on the fishery industries of the United States, and of Mr. Duff on the herring fisheries of Scotland.

It is not surprising that at the present moment suggestions should be offered from various sides to the Exhibition Committee with reference to the best use of the surplus funds in its hands. No one will pretend for a moment that the Committee has not the full right to make what use of those funds it may deem most fitting; and the public has every reason to feel confidence that the ultimate decision of the Committee will be made with the intention of doing what is best for the national interests bound up with our fishery industries. At the same time it is a legitimate thing for men of public position and responsibility to place before the Committee suggestions as to useful modes of employing the surplus funds in its hands. Accordingly we note with satisfaction that a number of our leading biologists, whose opinion upon this matter is certainly entitled to very great weight, have placed before the Committee a suggestion for the foundation of a laboratory upon the British coast, which shall be devoted to the study of marine animals and plants in relation to fisheries. A similar proposal has also been independently placed before the Exhibition Committee by the executive of the British Association for the Advancement of Science.

It is a very striking fact that the one point in which all speakers at the Conferences held during the past summer at the Exhibition were agreed was this: that our knowledge of the habits, time, and place of spawning, food, peculiarities of the young, migrations, \&c., of the fish which form the basis of British fisheries, is lamentably deficient, and that without further knowledge any legislation or attempts to improve our fisheries by better modes of fishing, or by protection or culture, must be dangerous, and indeed unreasonable. Prof. Brown Goode, the United States Commissioner, declared at the Conference on July 20 that "the spread of actual scientific knowledge concerning fish and fisheries was one of the things which, above all others, would be the most profitable and satisfactory outcome of this Exhibition." At the same Conference Prof. Hubrecht, the Netherlands Commissioner, said that "he endorsed from the bottom of his heart the principle that there must be inquiry, and still further inquiry, before legislation based on scientific and accurate principles could be carried out. They must take as a motto, more knowledge, more science, more zoology." On the same occasion the Duke of Argyll referred to the suggestion which had been submitted to the Conference to the effect that the foundation of a laboratory of marine zoology might well be undertaken by those who had organised and carried out the International Fisheries Exhibition. Speaking with the authority of one well acquainted with the Scotch herring fisheries, as well as with the knowledge of an accomplished naturalist, he stated that in his judgment this suggestion was a most important one, which be hoped would be brought forward in the proper quarter, and that he should give all the help he could in the matter. 
The memorandum which we print below briefly sets forth the proposal as now submitted to the Executive Committee of the Fisheries Exhibition. It has been signed by the following naturalists:- Sir John Lubbock, Mr. P. L. Sclater, Prof. Jeffrey Bell, Prof. Michael Foster, Prof. Burdon Sanderson, Prof. Flower, Prof. Allman, Prof. Richard Owen, Dr. G. I. Romanes, Prof. Lankester, Prof. Moseley, Dr. Carpenter, Mr. John Murray, Mr. Thiselton Dyer, Prof. Milnes Marshall, and Mr. Adam Sedgwick. The absence of the names of one or two influential zoologists from this list is explained by their official connection with the Exhibition, which has rendered it undesirable to ask them to commit themselves in reference to a question in the consideration of which they will ultimately have the greatest responsibility and weight.

The memorandum runs as follows :-

Proposal for the Foundation of an Observatory on the British Coast for the Siudy of Marine Animals and Plants in relation to Fish and Fisheries.

The value to the fish industry of an increased knowledge of the habits and life-history of fishes has been proved by the experience of the American and French Commissions. Without such knowledge we cannot improve our fisheries commercially; with it, there is every probability that a great deal may be done in the way of controlling and extending them. In order to gain accurate knowledge as to the circumstances which affect the life of fishes, and the various mollusks, shell-fishes, corals, and sponges, which are important commercially as well as interesting from the scientific point of view, it is necessary that continuous observations should be made upon their growth from the egg onwards, upon their food and its natural history, as well as upon their enemies and the conditions favouring, or injurious to, their life. Such observations can only be successfully carried out by persons resident on the sea-coast. In order to enable competent observers to spend such time as they can afford for these studies to the greatest advantage, zoological observatories have been established on the sea-coast of foreign countries, but at present there is no such observatory on the British coast. The first observatory of the kind is the "zoological station" established by Dr. Dohrn at Naples, which is frequented by naturalists from all parts of Europe. Its buildings and aquaria represent an expenditure of $20,000 \%$, and its annual expenditure is over $4000 l$. Similar observatories have been established by the Austrian Government at Trieste, and by the French Government at Concarneau, Roscoff, and Villefranche. It has been for some years the desire of English naturalists to establish a zoological observatory on the British coast, which would be in charge of a competent resident superintendent, and fitted with aquaria, Jaboratories, and apparatus, and possessed of boats and dredging apparatus. Two or three fishermen would be kept in the pay of the observatory. The institution thus organised would be frequented at all times of the year by naturalists desirous of carrying on original investigations relative to the life-history and structure of marine organisms. Accommodation for as many as six such naturalists might be provided. The affairs of the observatory and the granting of permission to make use of its appliances might be intrusted to a small committee, consisting (for example) in the first place of the Warden of the Fishmongers' Company, the professors of zoology, botany, and physiology in the universities of Great Britain, and in the London colleges, and the secretaries of the Linnæan and Zoological Societies of London. Were such an observatory once established, there is every reason to believe that funds could be raised annually for the purpose of extending its operations, and of carrying on special work in it by grants from scientific societies, the universities, and such sources. The obstacle hitherto to the establishment of a British zoological observatory has been the difficulty of obtaining the large sum necessary to launch the institution. It is calculated that $8,0 \mathrm{OcO}$. would be sufficient to secure a site and erect and furnish a suitable building-whilst $500 \mathrm{l}$, a year should be secured as a minimum income for the purpose of paying a salary of $250 l$. a year to a resident superintendent, minor salaries to fishermen and attendants, and of meeting the small current expenses. The income of the institution might be materially aided by the payment of a fee (say 5 l. a month) on the part of those naturalists making use of its resources. The opportunity for securing the $20,000 l$. necessary for the inauguration of such a zoulogical observatory has presented itself in connection with the International Fisheries Exhibition. Should there be, as there is reason to hope, a large surplus fund in the hands of the Committee of the Exhibition at its close, it is proposed to bring the suggestion of the establishment of a Marine Zoological Observatory before the Commitlee, and to endeavour to obtain the support of that body for the scheme. It is proposed that a deputation of scientific men should interview the committee of the Fisheries Exhibition, in order to explain the importance of a marine observatory and the close relationship of the work done in such an institution to the interests of our fisheries; and the Committee would then be asked to consider the propriety of handing over the sum of $20,000 /$. (or if possible a larger sum, this being a minimum) to trustees, for the purpose of building and endowing such an observatory, provision being made as to the future government and occupation of the observatory, as atove suggested.

\section{NOTES}

A $\mathrm{T}$ the opening of the London Hospital Medical School, Prof. Huxley gave an address on the relations of the State to the medical profession. He considers the present relations on the whole satisfactory, and that it is not desirable that the State should do more than it does to protect the public against incompetent persons and quacks. He thinks that no license should be granted except for the three qualifications, and that the course of study should be extended somewhat backwards, by insisting, instead of the general education test, upon some knowledge of elementary physics, chemistry, and so forth, by the young man desirous of entering upon a course of medical studies. In conclusion, he referred to the want of organisation for the advancement of the science of medicine considered as a pure science.

PROF. MICHAEL FOSTER gave the introductory address at the School of Pharmacy last week; the subject was "Cramming," and the address will be found reported in full in the Pharmacewtical Fournal of October 6.

THE remains of William Harvey are about to be removed to a new sarcophagus in Hemel Hempstead Church.

AN amusing incident is related in our contemporary L'Electricien, showing that the knowledge of electrical terminology is yet far from perfect amongst patrons of the latest applications of the science. One of the most eminent and old-established firms who supply incandescent lamps had lately fulfilled an order for a certain number of lamps, specified to be of twenty candle-power at forty-five volts. Thyy received, three days after despatching the goods, the following memorandum:- "We have received your lamps as per invoice, together with the supports, but we were unable to find amongst the goods consigned the forty-five volts invoiced with the lamps..." !

As the papers often refer to Chinese telegrams sent to and from Europe in connection with the Franco-Chinese negotiations, it may not be useless to state that a special code of telegraphy has been devised for the use of the Chinese. All the characters of the Chinese language have been numbered, and these numbers are sent by telegraph as secret messages. On arriving in China they are translated into Chinese numbers for the use of Chinese officials.

In carrying out an Act passed by Congress, President Arthur has invited the various countries to send representatives to an International Conference at Washington, the date of which is unfixed, to establish a common prime meridian. The Governments of Austria, Norway, and Sweden have declined, but the two latter approve of the object. Spain is favourable, but has deferred its reply. Belgium is uncertain, but Denmark and Portugal have accepted the invitation conditionally. Switzerland, Venezuela, Mexico, Turkey, Greece, China, Japan, Hawaii, Hayti, Liberia, Holland, Canada, Guatemala, Rou- 